\title{
Crucial Role for Early Growth Response-1 in the Transcriptional Regulation of miR-20b in Breast Cancer
}

\author{
Dongping Li ${ }^{1,2}$, Yaroslav Ilnytskyy ${ }^{1}$, Anna Kovalchuk ${ }^{1}$, Levon M. Khachigian ${ }^{3}$, \\ Roderick T. Bronson ${ }^{4}$, Bo Wang ${ }^{1,2}$ and Olga Kovalchuk ${ }^{1}$ \\ ${ }^{1}$ Department of Biological Sciences, University of Lethbridge, Lethbridge, Canada; \\ 2 Department of Biochemistry, Qiqihar Medical University, Qiqihar, P.R. China; \\ ${ }^{3}$ Centre for Vascular Research, University of New South Wales, Sydney, Australia; \\ ${ }^{4}$ The Dana Farber/Harvard Comprehensive Cancer Center, Boston, Massachusetts, USA. \\ Correspondence to: Olga Kovalchuk, email: olga.kovalchuk@uleth.ca \\ Bo Wang, email: bo.wang5@uleth.ca \\ Keywords: EGR1, miR-20b, transcription, PTEN, BRCA1, breast cancer, proliferation, migration, cell cycle arrest \\ Received: July 8, $2013 \quad$ Accepted: July 26, $2013 \quad$ Published: July 28, 2013
}

This is an open-access article distributed under the terms of the Creative Commons Attribution License, which permits unrestricted use, distribution, and reproduction in any medium, provided the original author and source are credited.

\section{ABSTRACT:}

Transcriptional regulation of miRNAs that control the pathogenesis of breast cancer remains largely unknown. Here, we showed that ionizing radiation, a known breast carcinogen, triggered the differential expression of miR-20b in mammary tissues. We identified several GC-rich consensus binding motifs for the zinc finger transcription factor early growth response-1 (EGR1) in miR-20b promoter. miR20b was upregulated by IR and its upregulation correlated with EGR1 expression in the breast cancer cell line HCC1806. Therefore, we used HCC1806 cells as a model system to explore the role of EGR1 in miR-20b transcription. siRNA knockdown of EGR1 attenuated miR-20b expression. Luciferase assays showed that whereas EGR1 stimulated luciferase activity driven by the wild-type miR-20b promoter, this induction was abolished in the mutant miR-20b promoter construct. We noted significant enrichment of EGR1 at miR-20b promoter in HCC1806 cells compared with normal human mammary epithelial cells. Suppression of miR-20b significantly inhibited HCC1806 cell proliferation and migration, and led to $G_{0} / G_{1}$ and $S$ phase arrest. In vitro RNA-pull down assays indicated that miR-20b targets numerous tumor suppressors, including PTEN and BRCA1, which were downregulated in HCC1806. Conversely, suppression of miR-20b increased PTEN and BRCA1 levels. Moreover, immunohistochemical and FISH analyses showed that the miR-20b expression correlated significantly with EGR1 levels in breast cancer tissues. Our findings thus demonstrate for the first time that EGR1 is a key player in the transcriptional control of miR-20b, and miR-20b may in turn function as an oncogene by contributing to breast tumorigenesis via tumor suppressor targeting.

\section{INTRODUCTION}

Breast cancer is the most common malignancy in women worldwide and the second leading cause of cancer-related deaths among North American women[1]. Most breast cancer patients undergo radiation diagnosis and are treated with radiotherapy. In addition to being an important treatment modality, ionizing radiation (IR) is a potent tumor-causing agent that has been linked to breast cancer development[2-4]. However, the exact molecular etiology of IR-induced mammary gland carcinogenesis remains unknown. Breast cancer is currently recognized as a genetic and an epigenetic disease[5]. The contribution of epigenetic alterations to breast carcinogenesis remains relatively obscure.

In recent years, one of the key advances in our understanding of the fundamental mechanisms of gene regulation has been the discovery of microRNAs 
(miRNAs/miRs). miRNAs are small noncoding RNA molecules that regulate gene expression either through translational repression or mRNA degradation, as determined by the degree of complementarity to the 3' untranslated regions of cognate mRNAs[6,7]. Approximately $30 \%$ of all protein-coding genes are assumed to be targets of miRNAs[8]. miRNAs possess diverse functions in many biologic and pathologic processes, including control of cell differentiation, proliferation, and apoptosis. Aberrant expression and dysregulation of miRNAs contribute to tumorigenesis, angiogenesis, and metastasis[6,9,10]. Current evidence indicates that miRNAs can serve as either tumor suppressors or oncogenes[11,12].

miRNA also partake in genotoxic stress responses. Many genotoxic carcinogens affect miRNA patterns in the exposed tissues and organs. Amongst those, IR profoundly affects tissue miRNAome. Recently we have shown that IR exposure affects mammary gland tissue and causes profound deregulation of miRNA expression. Amongst miRNAs, miR-20b was significantly affected.

miRNA-20b (miR-20b) is encoded by the miR106a-363 cluster which, together with the miR-17-92 and miR-106b-25 clusters, forms a large family of highly similar miRNAs called the miR-17 family[13]. Members of the miR-17 family are often upregulated in many human malignancies, such as lung cancer and leukemias[14-17]. Ectopic expression of miR-17 promotes motility and invasion of glioblastoma cells through targeting PTEN[18]. The high expression levels of miR-20b in gastric cancer constitute a negative survival prognostic factor[19]. miR-20b is upregulated in c-Myc-induced mouse mammary tumors[20]. Furthermore, several lines of evidence demonstrate that miR-20b downregulates $\mathrm{ER} \alpha$ (estrogen receptor alpha) [21] and modulates VEGF expression by targeting HIF-1 $\alpha$ and STAT3[22] in MCF7 breast cancer cells.

Transcriptional regulation of miR-20b in human cancers remains poorly understood to date. We therefore explored the transcription factor(s) involved in miR$20 \mathrm{~b}$ expression and the role of $\mathrm{miR}-20 \mathrm{~b}$ in breast tumorigenesis. The data presented in this paper indicate that IR induces miR-20b expression in rat mammary gland tissues in a dose- and time-dependent manner. We also show that miR-20b is upregulated in HCC1806 breast cancer cells, and this upregulation correlates with EGR1 expression. We provide evidence that EGR1 controls miR-20b transcription via putative EGR1 binding motifs present in miR-20b promoter. Suppression of miR-20b inhibits HCC1806 proliferation and migration, resulting in $\mathrm{G}_{0} / \mathrm{G}_{1}$ and $\mathrm{S}$ phase arrest. Furthermore, we provide the key evidence that miR-20b targets tumor suppressors BRCA1 and PTEN. Finally, immunohistochemical and FISH analyses indicate that miR-20b is elevated in 30\% of breast cancer and $50 \%$ of metastatic breast cancer specimens examined, and this upregulation correlates significantly with EGR1 levels.

\section{RESULTS}

\section{IR-induced miR-20b expression in mammary gland tissues and cells}

Our previous studies demonstrated that IR triggered a significant and sex-specific deregulation of the microRNAome, as well as altered levels of Dicer and components of the RNA-induced silencing complex in the spleen of C57BL/6 mice [23]. To understand the microRNAs that are differentially expressed in mammary gland tissues in response to IR, six-week old female Long Evans rats were exposed to different doses/energy X-ray and sacrificed at different time points after irradiation. microRNA microarray analysis showed that 96 hours after irradiation, miR-20b was significantly reduced (Fig. 1A). This result was confirmed by quantitative real-time RT-PCR (qRT-PCR, Fig. 1B). A similar response was also displayed in human mammary epithelial cells (HMEC) 96 hours post irradiation (Fig. S1A). The qRT-PCR using RNA samples from IR-exposed mammary gland tissues at different time points showed both a time- and dosedependent expression of miR-20b (Fig. 1C). IR also triggered a rapid and transient induction of miR-20b in HMEC cells which peaked at 24 hour post-IR (Fig. 1D and Fig. S1A), and correlated with the IR-inducible EGR-1 expression (Fig. 1E, Fig. S1B and C; correlation $\mathrm{r}=0.81926$ in $30 \mathrm{kVp} / 0.1$ Gy group; correlation $\mathrm{r}=0.68675$ in $80 \mathrm{kVp} / 2.5$ Gy group), although the EGR1 mRNA was not elevated at 6 hour post-IR. In consideration of the involvement of gene copy numbers in gene expression, we determined the changes in copy number in HMEC cells as a response to IR. However, our results showed that IR did not affect the copy number of miR-20b gene (Fig. S2), indicating the involvement of other mechanisms in the control of IR-inducible miR-20b transcription. Softwarebased bioinformatics analysis (Promoter 2.0 Prediction Server and Genomatix) identified several putative EGR1 binding motifs present in miR-20b promoter (Fig. 3A). We therefore hypothesized that EGR1 may play a role in miR$20 \mathrm{~b}$ transcription.

\section{EGR1 contributes to the transcriptional regulation of miR-20b in breast cancer cells}

To explore our hypothesis, we determined the expression of EGR1 and miR-20b, as well as the contribution of EGR1 to miR-20b transcription in breast cancer cells. qRT-PCR showed an aberrant expression of miR-20b in the breast cancer cell lines examined (Fig. 2A), which correlated with EGR1 expression (Fig. 2B), with the exception of MCF7. Knockdown of EGR1 in 
HCC1806 cells with the use of siEGR1 (siRNA targeting EGR1) resulted in a reduction in miR-20b expression (Fig. 2C and D). This reduction was particularly potent at the $50 \mathrm{nM}$ siEGR1 dose (Fig. 2D). Ectopic expression of Egr1 caused induction in luciferase activity in a reporter construct harboring the wild-type miR-20b promoter in a dose-dependent fashion. This EGR1 responsiveness was completely abolished in the mutant construct (Fig. 3B). EGR1 was overexpressed in HCC1806 cells (Fig. 2B), and both real-time ChIP-PCR and conventional ChIP-PCR indicated that EGR1 was functionally enriched at miR-20b promoter in HCC1806 cells compared with normal HMEC (Fig. 3C). Furthermore, EMSA assays indicated that EGR1 specifically bound to miR-20b promoter (Fig. 3D). Taken together, these results suggested that EGR1 played a crucial role in controlling miR-20b transcription. We then determined the role of miR-20b in breast carcinogenesis.

\section{miR-20b is a key player in breast cancer cell proliferation, migration, and cell cycle control}

Because of the upregulation of miR-20b in HCC1806 cells, we selected this cell line as a model system to functionally suppress miR-20b with the use of specific inhibitors. HCC1806 cell proliferation was significantly suppressed by miR-20b inhibitor in an MTT assay (Fig. 4A), and HCC1806 cell migration was likewise inhibited in a wound healing assay (Fig. 4B and C). Inhibition of miR-20b also interestingly resulted in $\mathrm{G}_{0} /$ $\mathrm{G}_{1}$ and $\mathrm{S}$ phase cell cycle arrest (Fig. 4D), although miR$20 \mathrm{~b}$ inhibitor did not affect apoptosis (Fig. S3). To identify the target molecules of miR-20b that may be involved in these pathological processes, molecules that bind to miR$20 \mathrm{~b}$ were pulled down in vitro and subjected to deep sequencing analysis. Software predictions by MIRANDA and RNAhybrid showed that miR-20b could bind to the 3' UTRs of many tumor suppressors (Fig. 5A) that are primarily associated with cell proliferation, invasion, apoptosis, and cell cycle control. Among the predicted targets of miR-20b, phosphatase and tensin homolog (PTEN, Fig. 5B) and breast cancer 1 gene (BRCA1, Fig. $5 \mathrm{~B})$ are critical in the maintenance of genomic stability, negative regulation of proliferative signaling, and prevention of cancer. Western blot analysis showed that PTEN and BRCA1 were downregulated in HCC1806 cells compared with HMEC, and that were inversely correlated

A

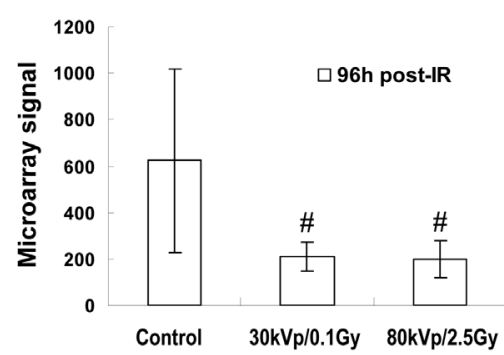

D
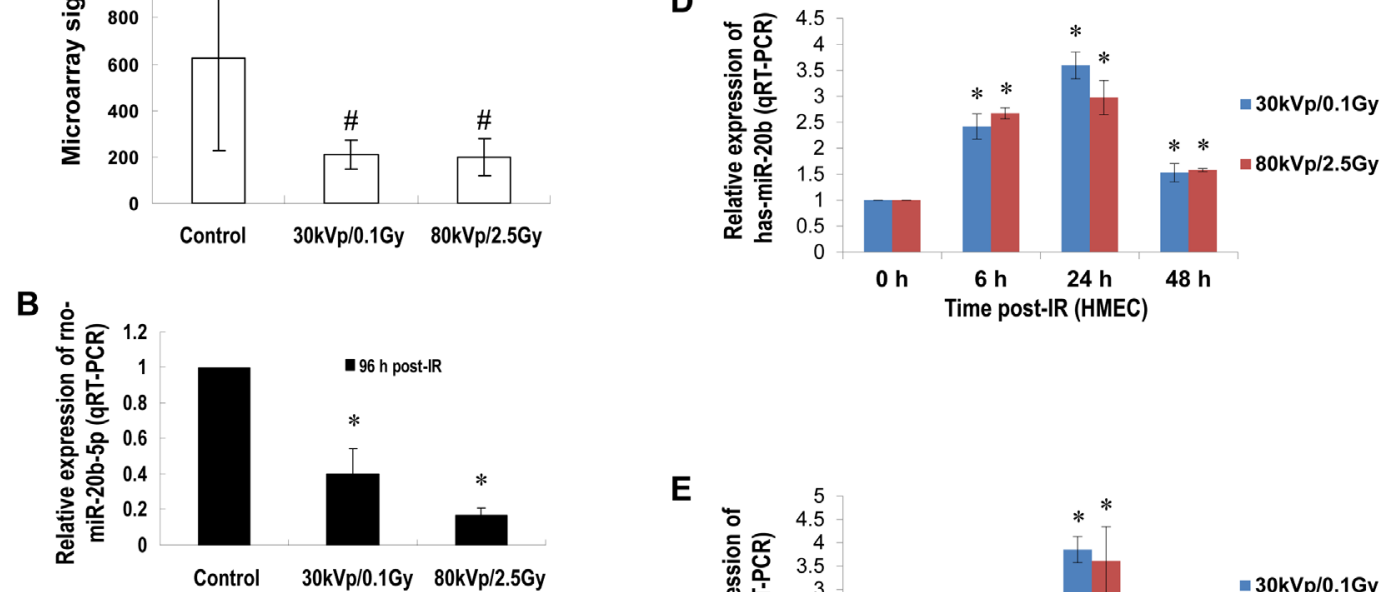

E
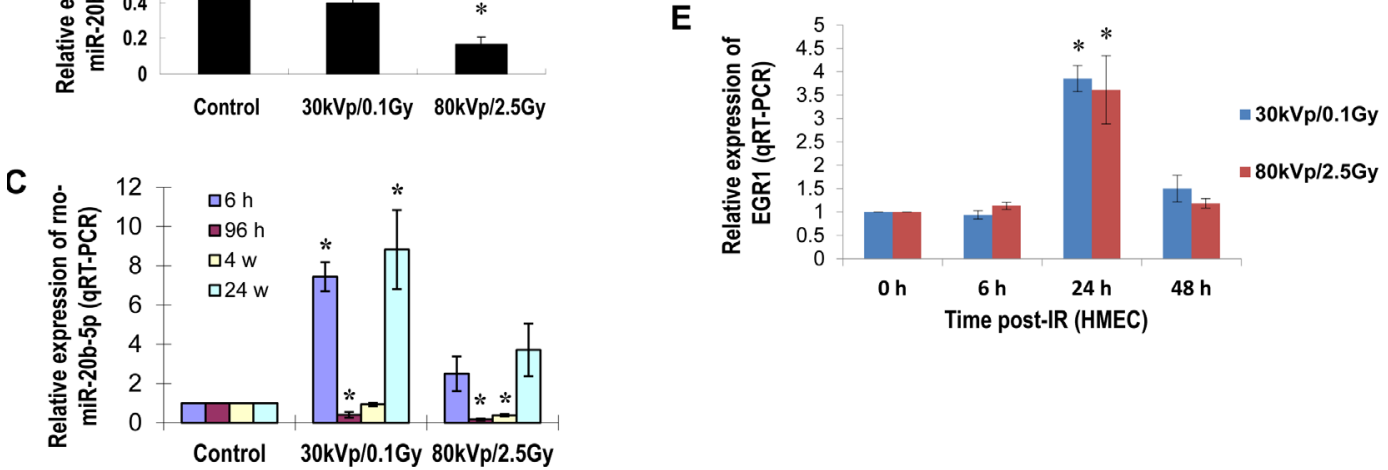

Figure 1: IR induces miR-20b expression in mammary gland tissues/cells in a dose- and time-dependent manner. (A and B) Total RNA isolated from the mammary gland tissues of six-week-old female Long Evans rats exposed to either $30 \mathrm{kVp} / 0.1 \mathrm{~Gy}, 80$ $\mathrm{kVp} / 2.5$ Gy X-ray, or sham-treatment 96 hours post-irradiation was subjected to microRNA microarray; the levels of rno-miR-20b were determined by real-time RT-PCR. (C) Total RNA was isolated from the mammary gland tissues of six-week-old female Long Evans rats at different time points post-IR, and the levels of rno-miR-20b were examined by real-time RT-PCR. (D and E) Total RNA isolated from HMEC exposed to either $30 \mathrm{kVp} / 0.1 \mathrm{~Gy}$ or $80 \mathrm{kVp} / 2.5$ Gy X-ray was subjected to real-time RT-PCR using primers for hsa-miR-20b and EGR1. The hash indicates $p<0.1$; the asterisk indicates $p<0.05$. 
with miR-20b expression in these cell lines (Fig. 5C, Fig. $2 \mathrm{~A})$. By contrast, suppression of miR-20b resulted in an elevation of the aforementioned proteins in HCC1806 cells (Fig. 5C). Luciferase activity in both pGL3-PTEN and pGL3-BRCA1 reporters was significantly reduced by miR-20b (Fig. 5D), suggesting that PTEN and BRCA1 were direct targets of miR-20b.

\section{EGR1 expression correlates with miR-20b expression in breast cancer specimens}

To further confirm the role of EGR1 in miR-20b transcription in diseased tissues, immunohistochemical staining and FISH analysis were performed to determine the expression of EGR1 and miR-20b in breast cancer tissue arrays. EGR1 was upregulated in $40 \%$ breast cancer tissues, and miR-20b was elevated in 30\% breast cancer tissues examined: upregulated EGR1 correlated significantly with upregulated miR-20b in the normal, benign, and tumor tissues tested (Fig. 6A and $\mathrm{B} ; \mathrm{r}=0.99, \mathrm{p}=0.032$ ). Likewise, downregulation of EGR1 also correlated with downregulated miR-20b in
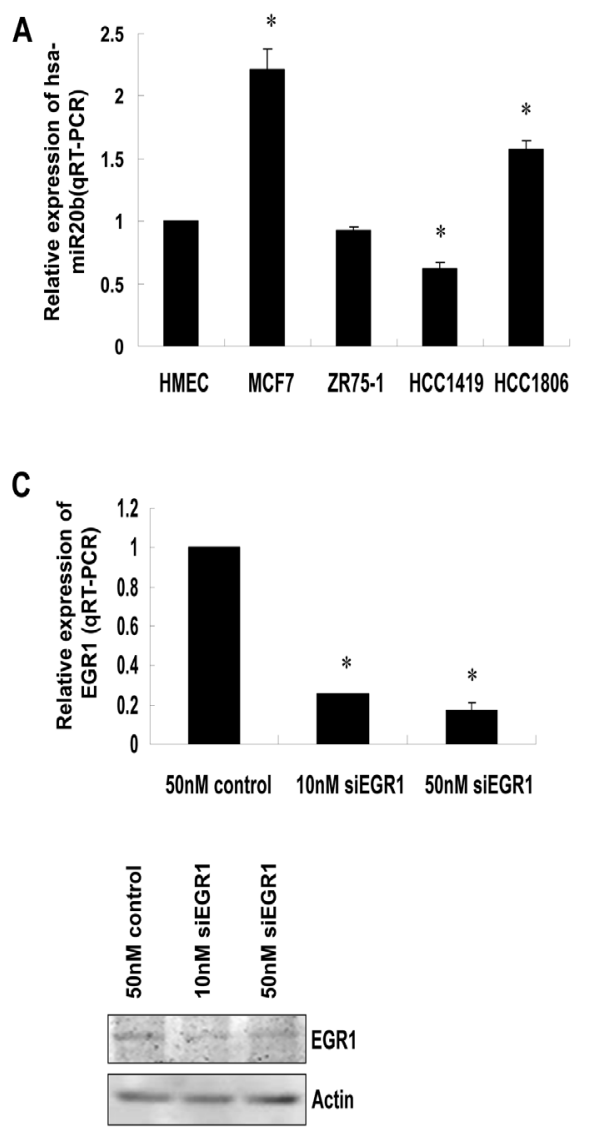

the normal, benign, and tumor tissues examined (Fig. $6 \mathrm{~A}$ and $\mathrm{B} ; \mathrm{r}=0.99, \mathrm{p}=0.054)$. More important, EGR1 was overexpressed in $50 \%$ of the metastatic breast cancer tissues examined. Once again, this overexpresion correlated strongly with an upregulation of miR-20b (Fig. $6 \mathrm{C}$ and D). These results further confirm the role of EGR1 in the transcriptional control of miR-20b and that aberrant expression contributed to the development of breast cancer, particularly metastatic breast cancer.

\section{Expression of PTEN and BRCA1 is negatively correlated with miR-20b expression in metastatic breast cancers}

To determine if the differentially expressed miR$20 \mathrm{~b}$ contributes to the expression of PTEN and BRCA1 in breast cancer, we further looked at the levels of their expression in breast cancer cell lines and breast cancer tissue arrays. Western blot analysis showed that levels of PTEN and BRCA1 were downregulated in all breast cancer cell lines examined (Fig. S4). While only in MCF7 and HCC1806 lines $(50 \%, n=4)$, the levels of PTEN
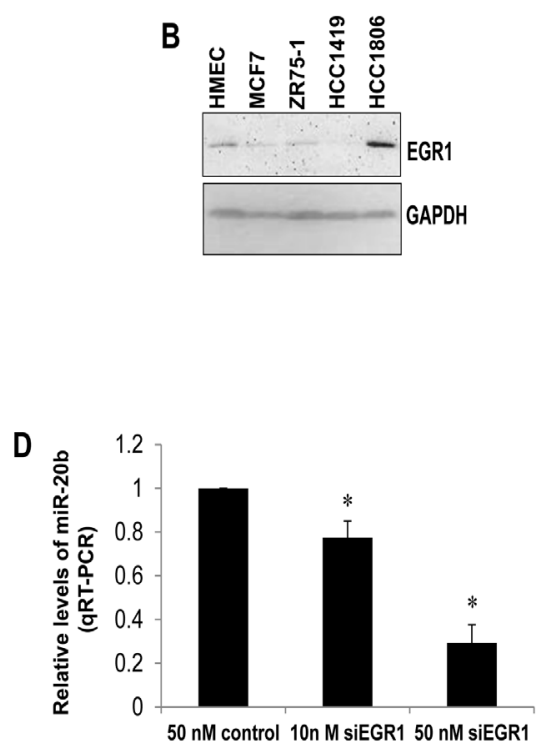

Figure 2: EGR1 correlates with miR-20b expression levels. (A) Total RNA isolated from HMEC and breast cancer cell lines MCF7, ZR75-1, HCC1419, and HCC1806 was subjected to real-time RT-PCR with a primer set for miR-20b. (B) Whole cell lysates prepared from the above cell lines were subjected to Western blot analysis using antibodies against EGR1 and GAPDH. (C) HCC1806 cells were transiently transfected with either siEGR1 (siRNA targeting EGR1) or control siRNA; the levels of EGR1 mRNA and protein were determined by real-time RT-PCR (upper panel) and Western blot analysis (lower panel). (D) HCC1806 cells were transiently transfected with either siEGR1 or control siRNA; the levels of miR-20b were determined by real-time RT-PCR. The asterisk indicates $p<0.05$. 
and BRCA1 are negatively correlated with the miR-20b expression (Fig. 2A). Immunohistochemical analysis indicated that PTEN and BRCA1 are downregulated in $47 \%$ and $77.8 \%$ of metastatic breast cancer tissues, respectively (Fig. S5 and S6), and the levels of PTEN and BRCA1 were both negatively correlated with the miR-20b expression (Fig. 6D) ( $\mathrm{r}=-0.996$ and -0.778 , respectively). Furthermore, the levels of PTEN and BRCA1 in normal and benign breast tissues were also negatively correlated with the miR-20b expression (Fig. S7 and S8, and Fig. 6B) (Normal: $r=-0.949$ and -0.749 , respectively; benign: $\mathrm{r}=-0.761$ and -0.52 , respectively). However, no correlation was found in malignant breast cancer tissues. These results suggest that miR-20b contributes, at least in part, to the aberrant expression of PTEN and BRCA1 in breast cancer.

\section{DISCUSSION}

In recent years, small noncoding RNAs, especially miRNAs, have been extensively investigated as possible key players in the process of breast cancer development and breast cancer treatment responses. However, all research efforts have primarily focused on identifying genes that miRNAs target and affect. Little is known about how miRNA transcription is regulated. A better understanding of the mechanisms that regulate miRNA transcription would provide an essential backdrop for future interventional approaches.

This study for the first time demonstrated that EGR1 regulated miR-20b transcription and provided important clues on the role of miR-20b in breast tumorigenesis (Fig. 7 ). Breast cancer is a multifactorial and multistage process that involves many environmental and genetic factors. Among the environmental factors that cause breast cancer, IR may be one of the high-risk factors because it has been shown to strongly induce breast cancer in exposed individuals[2]. Furthermore, the IR-induced mouse breast cancer model has been widely used in the field of breast cancer research. Unfortunately, the epigenetic mechanisms underlying IR-induced mammary carcinogenesis largely remain unknown. We showed in this paper that IR triggered miR-20b expression in mammary gland tissues in a dose- and time-dependent manner (Fig. 1C). Although IR is a putative inducer of genomic instability, including gene amplification [24], miR-20b gene copy number in our case did not contribute to IR-induced miR-20b expression (Fig. S1 and Fig. 1D).

Interestingly, bioinformatic analysis showed several putative EGR1 binding motifs present in miR$20 \mathrm{~b}$ promoter, and EGR1 expression was correlated with miR-20b expression in HMEC cells in response to IR, suggesting a role of EGR1 in miR-20b transcription. Our deduction was confirmed by experiments performed on breast cancer cell lines, in which miR-20b expression
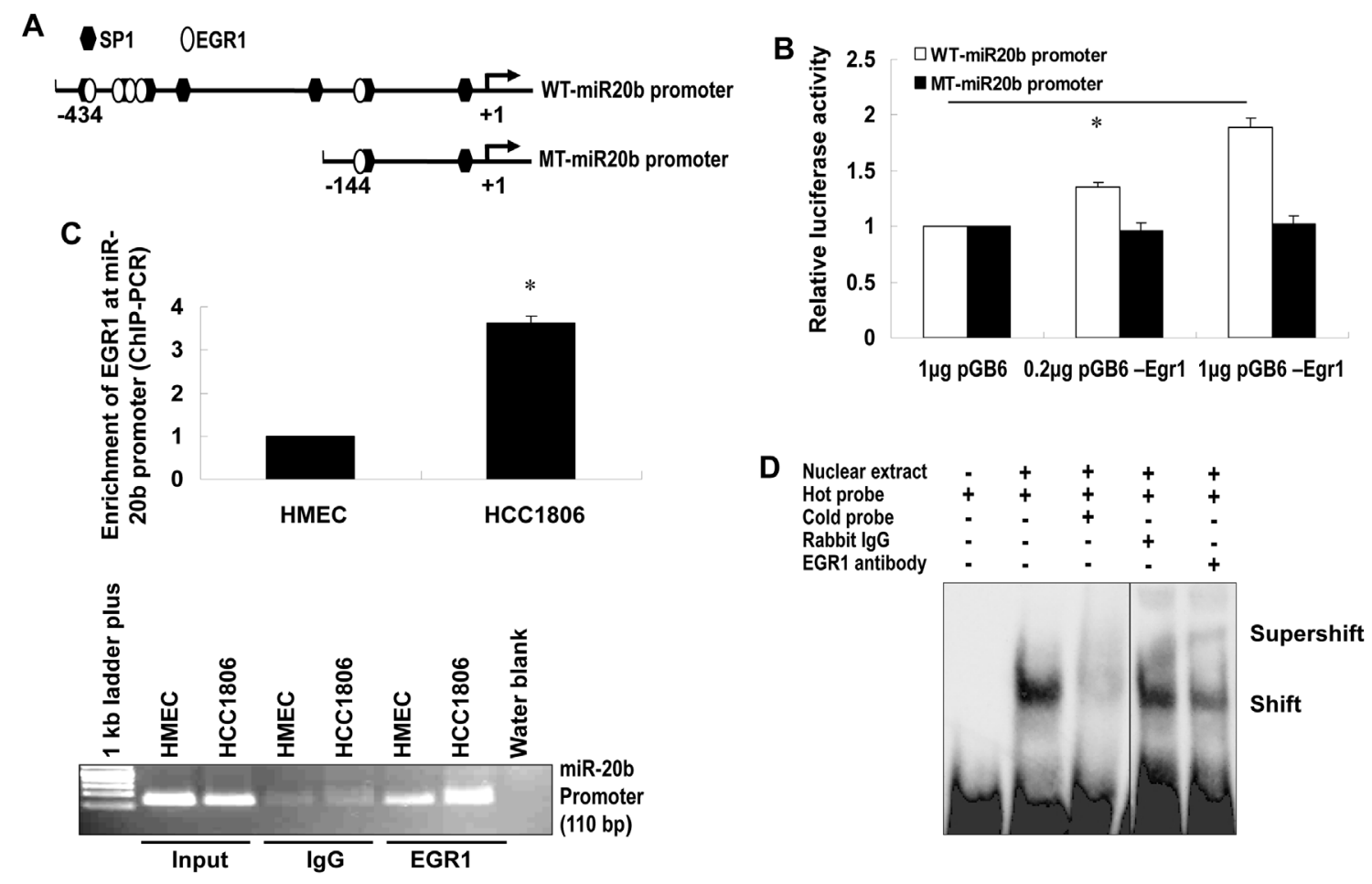

Figure 3: EGR1 regulates miR-20b transcription. (A) The wild-type and mutant miR-20b promoter reporters used in this project. (B) HEK293 cells were transiently transfected with pGL3-WT-miR20b-Prom or pGL3-MT-miR20b-Prom and pCB6-Egr1 or pCB6; luciferase activity was detected according to the manufacturer's instruction. (C) Real-time ChIP-PCR and conventional ChIP-PCR were performed as described in "Materials and Methods". (D) Nuclear extracts were prepared from HCC1806 cells, and EMSA was performed using ChIP-grade antibody to EGR1 according to the manufacturer's instruction. The asterisk indicates $p<0.05$. 
was positively correlated with EGR1 expression in the cell lines examined, except for MCF7. Furthermore, knockdown of EGR 1 resulted in a reduction in miR-20b expression. The regulation of gene expression is known as a complex process in which numerous mechanisms are involved, such as genetics, epigenetics and molecular biology, transcriptional and post-transcriptional levels. In MCF7, the EGR does not appear to contribute to the miR-20b transcription. That, however, may reflect the involvement of other transcription factors or mechanisms.

EGR1 is a zinc finger transcription factor that plays a crucial role in controlling cell growth, proliferation, differentiation and apoptosis [25-29]. EGR1 regulates transcription of target genes by binding to $\mathrm{GC}$-rich consensus DNA elements present in the regulatory regions. EGR1 is induced in response to a wide range of extracellular stimuli that includes growth factors, cytokines, ionizing radiation, UV light, and mechanical injury [30-33]. Growing evidence indicates that EGR1 activation may serve as a key switch in many pathological processes, including cardiovascular disease and cancers. EGR1 has been indicated in the progression of breast, colon, prostate and esophageal cancers[34-38]. Elevated EGR1 in esophageal cancer plays an important role in mediating and maintaining growth-related oncogene/
CXC chemokine receptor 2 proliferative signaling[34]. EGR1 is overexpressed in primary human prostate carcinomas [36,37], and several EGR1 target genes (e.g. insulin-like growth factor II, transforming growth factor $\beta 1$, and platelet-derived growth factor A-chain) have been implicated in prostate tumorigenesis [37]. Knockdown of EGR1 suppresses prostate cancer cell proliferation and tumor development in transgenic adenocarcinoma mouse prostate mice [39]. Furthermore, DNAzymes targeting EGR1 inhibit breast cancer cell proliferation, migration and tumor growth in nude mice [38] although the underlying mechanisms are still unclear. Here, we provide evidence to show that miR-20b is a direct target of EGR1. Our findings demonstrate that EGR1 is associated with miR-20b expression in IR-exposed HMEC cells, breast cancer cell lines and tissues examined, and that EGR1 interacts with the miR-20b promoter and functionally regulates miR-20b transcription. Although here we only discuss the oncogenic role of EGR1, several lines of evidence have indicated a tumor suppressor role in both p53-dependent and-independent apoptosis [40,41].

Although this is the first report regarding EGR1 in the transcriptional regulation of miR-20b, EGR1 was previously reported to regulate mir-106a expression[42]. This result suggested that in addition to the well-defined
A

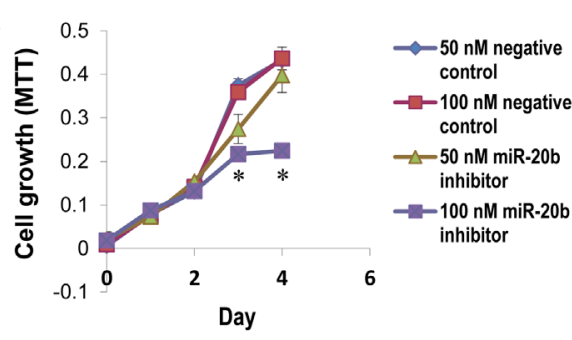

B

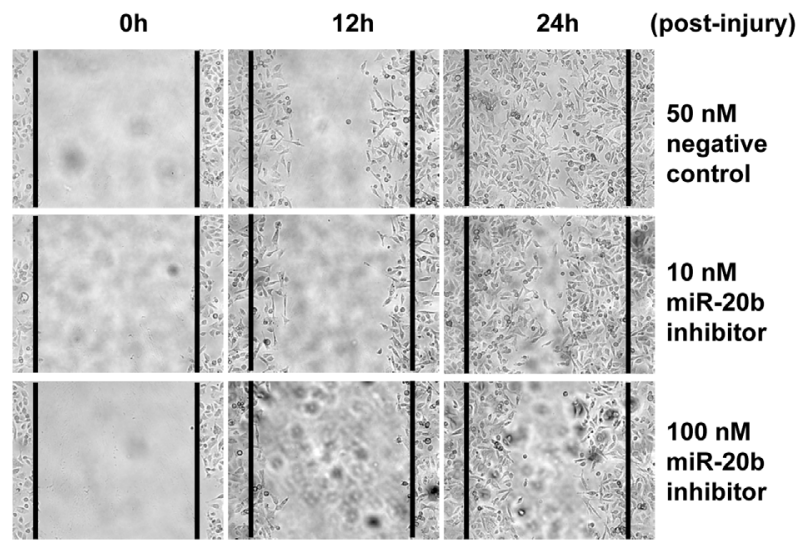

D

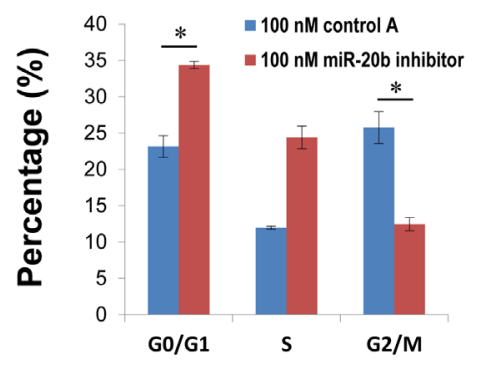

Figure 4: miR-20b inhibitor suppresses breast cancer cell proliferation and migration, as well as induces $\mathbf{G}_{\mathbf{0}} / \mathbf{G}_{\mathbf{1}}$ and S phase arrest. (A) HCC1806 cells were transfected with either miR-20b inhibitor or a negative control; MTT assay (cell proliferation assay) was performed according to the manufacturer's instruction. (B and C) HCC1806 cells were transfected with either miR-20b inhibitor or negative control; 24 hours after transfection, wound-healing assay and statistical analysis of migrated cells were performed. (D) HCC1806 cells were transfected with either miR-20b inhibitor or negative control; 96 hours after transfection, cell cycle analysis was conducted using DB FACSCanto II Flow Cytometer. The asterisk indicates $p<0.05$. 
mRNA transcription, EGR1 may play a critical role in the transcriptional control of miRNAs of miR-17 family. The latters may be important in mediating the biological functions of EGR1.

The absence of ER $\alpha$ in breast carcinomas has been known for years to be associated with a less-differentiated phenotype and with resistance to endocrine therapies, thus presenting poor prognosis. A recent study identified a new modulator of $\mathrm{ER} \alpha$, miR-20b, which downregulated $\mathrm{ER} \alpha$ in
MCF7 breast cancer cells [21]. However, the role of miR$20 \mathrm{~b}$ in breast tumorigenesis remains elusive.

We showed here that miR-20b inhibitor dramatically suppressed HCC1806 breast cancer cell proliferation and migration resulting in a $\mathrm{G}_{0} / \mathrm{G}_{1}$ and $\mathrm{S}$ phase arrest in cell cycle that clearly indicated the key role of miR-20b in the development of this disease. To globally identify miR-20b targets associated with cell proliferation, migration, and cell cycle control, in vitro RNA pulldown and deep RNA

A

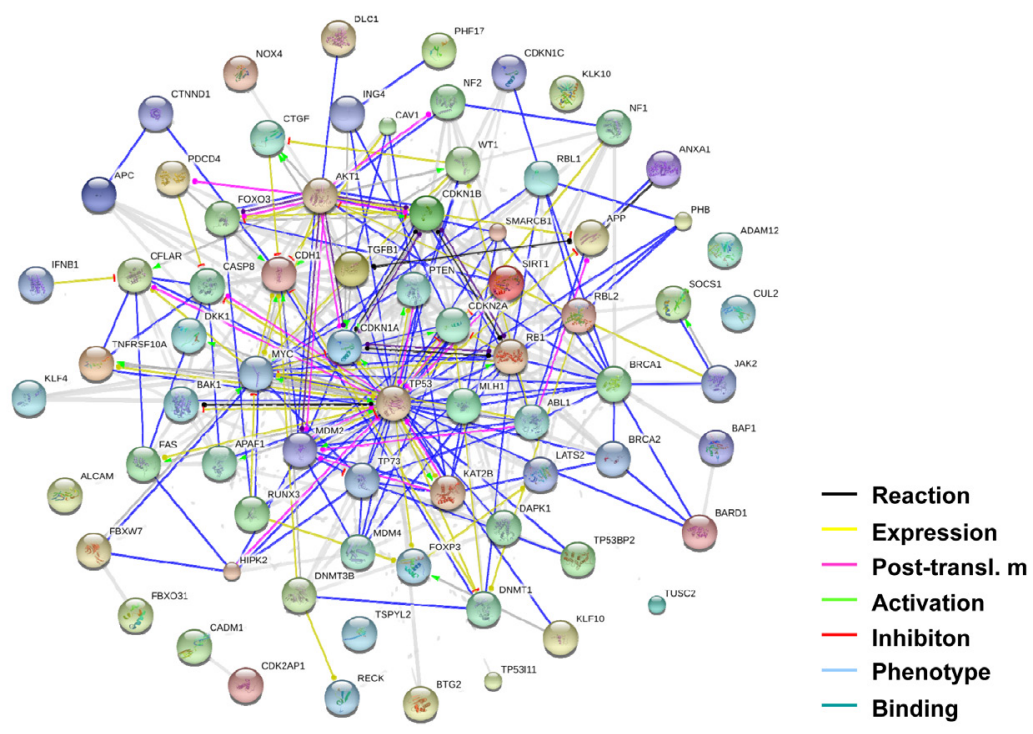

B

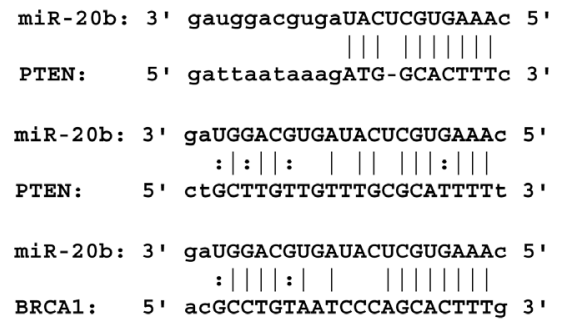

C

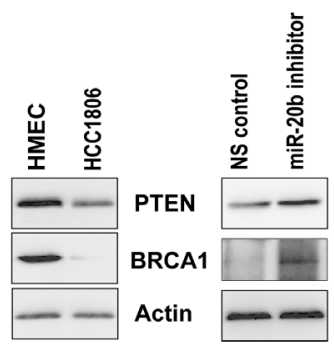

D
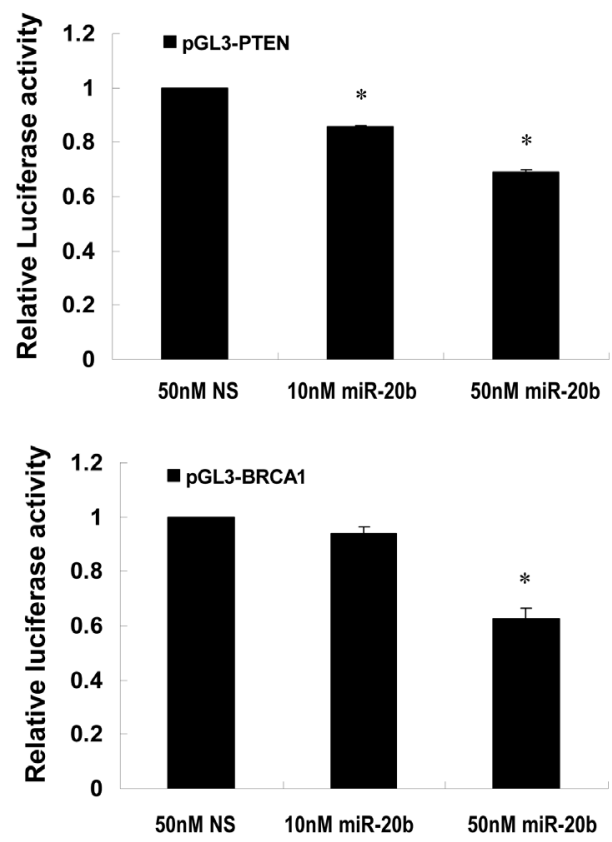

Figure 5: PTEN and BRCA1 are direct targets of miR-20b. (A) The network of the predicted targets of hsa-miR-20b was generated using STRING 9.0. (B) Diagram of 3'UTR sequences of PTEN and BRCA1 targeted by hsa-miR-20b. (C) Whole cellular lysates prepared from HMEC, HCC1806, and HCC1806 transfected with either $50 \mathrm{nM}$ miR-20b inhibitor or non-specific control for 72 hours were subjected to Western blot analysis using antibodies specific to PTEN and BRCA1. (D) HEK293 cells grown to $90 \%$ confluency were cotransfected with either pGL3-PTEN or pGL3-BRCA1 reporter, and the indicated concentration of hsa-miR-20b or $50 \mathrm{nM}$ nonspecific miRNA as a control; 24 hours after transfection, luciferase activity was detected using Dual-Luciferase Reporter Assay System according to the manufacturer's instruction. The asterisk indicates $p<0.05$. 
sequencing analyses were performed. Our results indicated that miR-20b could target many tumor suppressors (Fig. 5A), including PTEN and BRCA1, which were of a particular interest to us (Fig. 5B), since the inhibitory role of these two genes in proliferation, migration, and cell cycle has been well documented [43-49]. PTEN is frequently mutated in human primary tumors and cell lines. The involvement of PTEN in human mammary tumorigenesis has been demonstrated from studies showing that germline PTEN mutations in Cowden
A
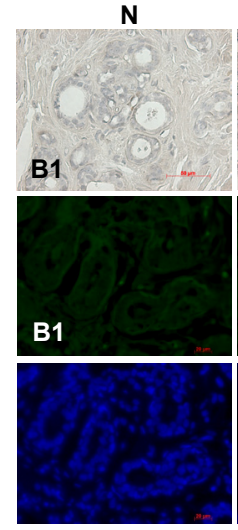

Downregulated

B

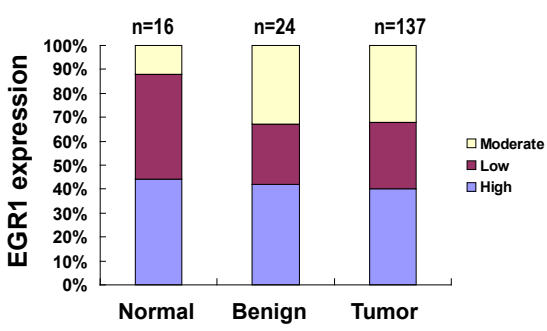

$\mathbf{N}$
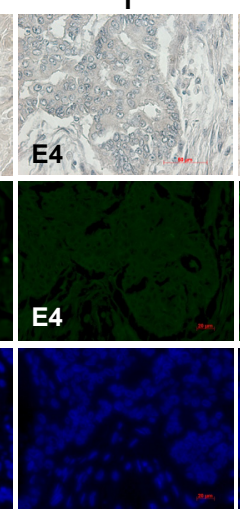

A2

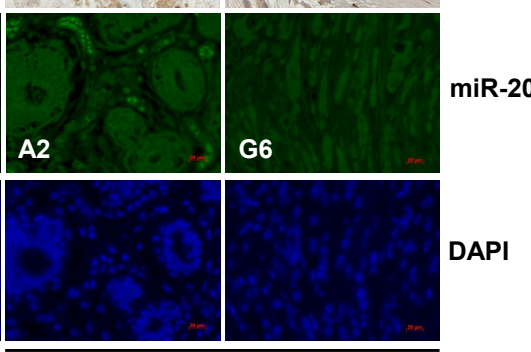

Upregulated

$\mathbf{T}$

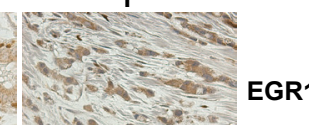

G6

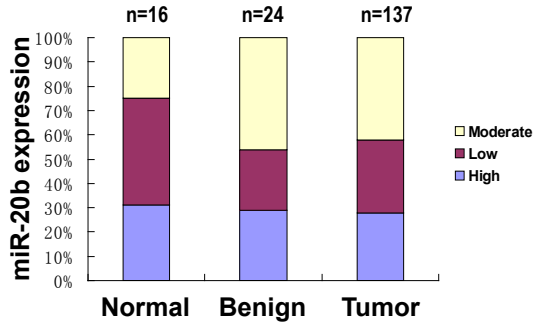

C

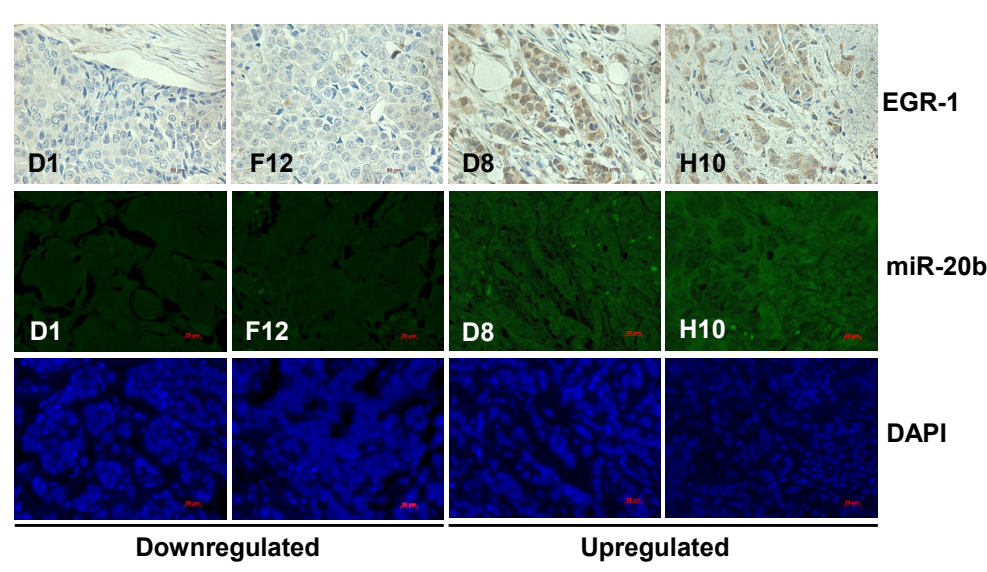

D
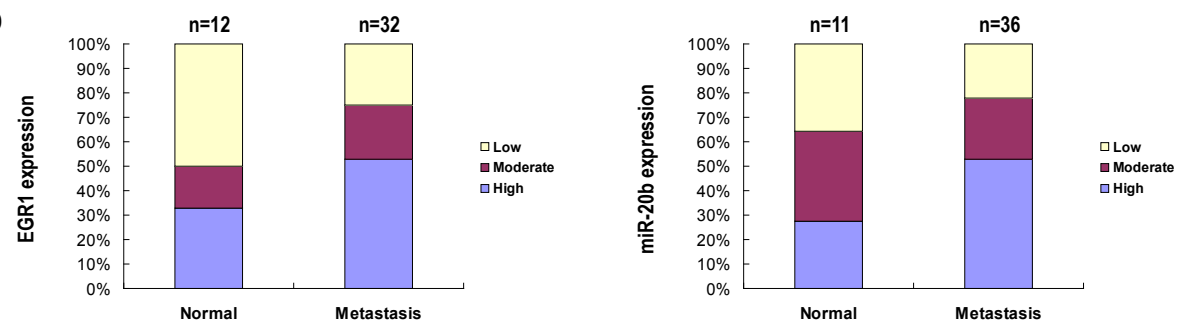

Figure 6: EGR1 expression is correlated with miR-20b expression in breast cancer tissues. (A) Representatives of EGR1 and hsa-miR-20b stainings in the same sections of breast cancer tissue arrays. (B) Statistical and correlation analyses of EGR1 and hsamiR-20b expression in breast cancer tissues. (C) Representatives of EGR1 and hsa-miR-20b staining in the same sections of metastatic breast cancer tissue arrays. (D) Statistical and correlation analyses of EGR1 and hsa-miR-20b expression in metastatic breast cancer tissues. 
disease predisposes afflicted individuals to breast cancer. The frequent loss of heterozygosity at the PTEN locus and reduced PTEN protein levels are often seen in sporadic breast cancers [43]. Germline mutation of BRCA1 frequently leads to hereditary breast and ovarian cancer (HBOC) syndrome, which accounts for $5 \%$ to $7 \%$ of all breast cancer cases. Individuals with HBOC syndrome have a $50 \%$ to $80 \%$ lifetime risk of developing breast cancer [44], suggesting the crucial role of loss-function of BRCA1 in the development of breast cancer. We showed in this paper that the expression of PTEN and BRCA1 was downregulated in HCC1806 breast cancer cells compared with HMEC cells, and this diminished presence was negatively correlated with miR-20b expression in such cell lines. Conversely, suppression of miR-20b with the use of its inhibitor remarkably enhanced the protein levels of PTEN and BRCA1 in HCC1806 cells (Fig. 5C). Furthermore, PTEN and BRCA1 are both downregulated in metastatic breast cancer tissues (Fig. S5 and S6), and that is negatively correlated with miR-2b expression in these tissues (Fig. 6D). Moreover, luciferase assays confirmed that PTEN and BRCA1 3' UTRs were direct targets of miR-20b (Fig. 5D). The expression of PTEN and BRCA1 in ZR75-1 and HCC1419 breast cancer cells and malignant breast cancer tissues (Fig. S4, S7 and S8), however, was not negatively correlated with the miR-20b expression (Fig. 2A and 6B), implicating the involvement of other factors/mechanisms in the expression of PTEN and BRCA1, in addition to miR-20b. Transcription factors, miRNAs and target proteins may form a complex network that plays an essential role in biologic and pathologic processes [50]. Although here we only showed that miR- 20b transcriptionally activated by EGR1 directly targets PTEN and BRCA1, PTEN may also be directly activated by EGR1 [51], and BRCA1 may also play a role in the expression of other microRNAs, such as miR-155 [52].

To further establish the relationship between EGR1 and miR-20b expression in a large amount of breast tissue samples, we performed immunohistochemical and FISH analyses of EGR1 and miR-20b on breast cancer tissue arrays. Our data indicated that EGR1 expression was significantly correlated with miR-20b expression in normal, benign, and breast cancer tissues (Pearson Correlation $\mathrm{r}=0.99$, Fig. $6 \mathrm{~A}$ and B). Furthermore, both EGR1 and miR-20b were overexpressed in 50\% metastatic breast cancer tissues compared with normal tissues and were correlated with each other remarkably well (Fig. 6C and D). These results further confirmed the relationship between EGR and miR-20b expression, as well as the involvement of miR-20b in the metastasis of breast cancer cells. Although normal tissues adjacent to tumors are generally used in comparative studies, it may be debateable whether or not the adjacent normal breast tissues used in these studies were really "normal". A recent report indicated that the "normal" tissue adjacent to pancreatic cancer has already acquired a number of transcriptional alterations, and therefore is not an appropriate baseline for comparison with cancers[53]. This may partially explain why EGR1 and miR-20b are elevated $44 \%$ and $31 \%$, respectively, in adjacent normal breast tissues examined $(n=16)$. Although we did not analyze the correlation between miR-20b and triplenegative primary breast cancers due to the restriction in clinical data, other miRNAs, such as miR-21, miR-210

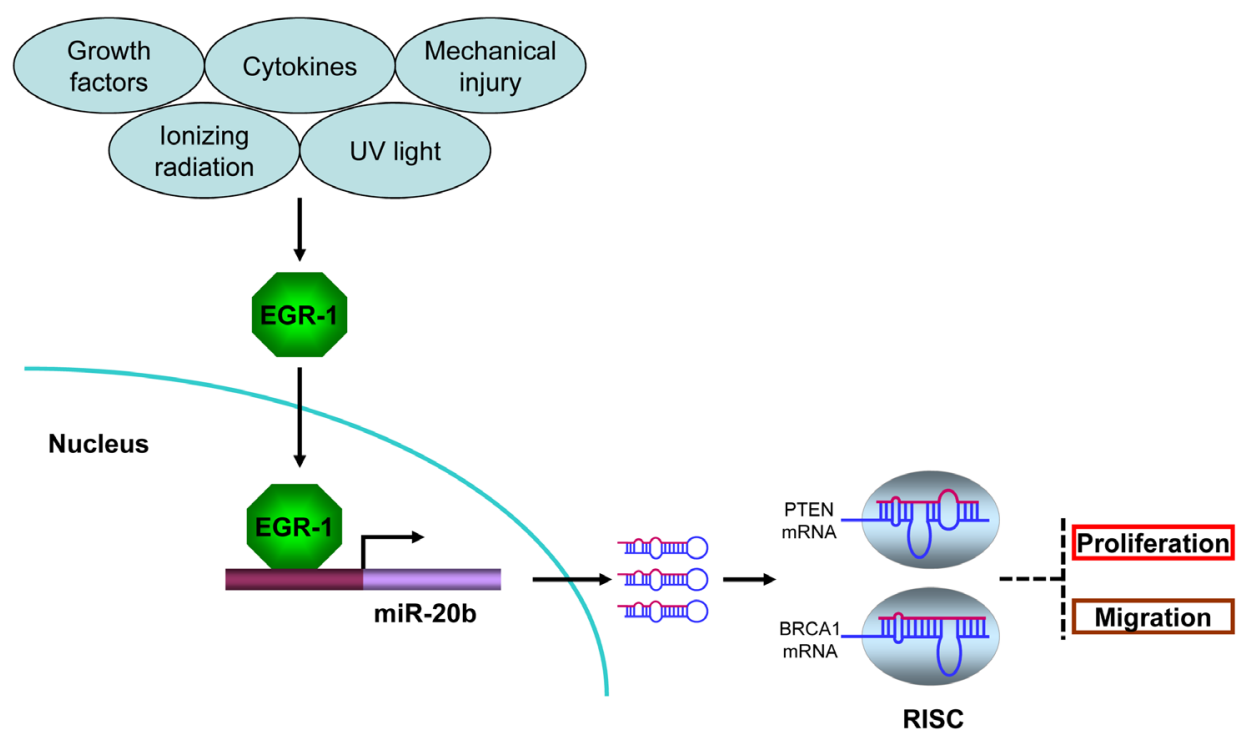

Figure 7: miR-20b transcriptionally activated by EGR1 directly targets PTEN and BRCA1 in breast cancer. Seruminducible zinc finger transcription factor EGR1 is induced and activated in response to a wide range of extracellular stimuli, including growth factors, cytokines, UV light, ionizing radiation, and mechanical injury. Once activated, EGR1 translocates into nucleus and binds to the consensus motifs at miR-20b promoter, leading to miR-20b transcription. The mature miR-20b assembles with other proteins to form RNA-induced silencing complex (RISC), the later recognizes and binds to PTEN and BRCA1 mRNAs, leading to either translational suppression or degradation of those two molecules, consequently resulting in breast cancer cell proliferation and migration. 
and miR-221 have been reported to play a significant role in these breast cancers[54].

In summary, the transcription factor EGR1 is a key regulator in the transcriptional control of miR-20b, which is aberrantly expressed in breast cancer tissues and cell lines. miR-20b may serve as an oncomiR that plays a crucial role in breast tumorigenesis by targeting tumor suppressors PTEN and BRCA1.

\section{MATERIALS AND METHODS}

\section{Animal irradiation}

Six-week old female Long Evans rats were randomly assigned to different treatment groups. Group 1: $30 \mathrm{kVp}$ X-ray, 0.1 Gy (low dose/low energy, cumulative dose from multiple mammography screen); Group 2: 80 kVp X-ray, 2.5 Gy (High dose/high energy); and, Group 3: sham-treated controls. Ten rats per group were sacrificed at 6 hours, 96 hours, 4 weeks or 24 weeks after irradiation. Mammary gland specimens were frozen immediately and stored at $-80^{\circ} \mathrm{C}$, or fixed in $10 \%$ neutral buffered formalin and embedded in paraffin. Handling and care of animals were in accordance with the recommendations of the Canadian Council for Animal Care and Use. Procedures were approved by the University of Lethbridge Animal Welfare Committee. Animals were housed in a virus-free facility and given food and water ad libitum.

\section{microRNA profiling}

Total RNA was isolated from mammary gland tissue of different group IR-exposed rats using TRIzol reagent (Invitrogen) according to the manufacturer's instruction. MicroRNA profiling, clustering and data analysis were carried out by LC Sciences.

\section{Cell culture}

Human mammary epithelial cells (HMEC) purchased from Invitrogen were cultured in HuMEC Basal Serum-Free Medium (Invitrogen) containing HuMEC Supplement (Invitrogen); breast cancer cell lines ZR75-1, HCC1419, and HCC1806 obtained from ATCC were grown in ATCC-formulated RPMI-1640 Medium (ATCC) containing 10\% FBS; MCF7 cells were cultured in DMEM/F-12 (HyClone) containing 10\% FBS; HEK293 cells were grown in DMEM/High Glucose (Thermo Scientific Limited) containing $10 \% \mathrm{FBS}$ at $37^{\circ} \mathrm{C}$ in a humidified atmosphere of $5 \% \mathrm{CO}_{2}$.

\section{microRNA real-time RT-PCR}

Total RNAs isolated from IR-exposed rat mammary gland tissue, HMEC, MCF7, ZR75-1, HCC1419, and HCC1806 cells were subjected to real-time RT-PCR using primer sets for either rno-miR-20b-5p or hsa-miR20b (SABiosciences) according to the manufacturer's instruction. Rat and human RNU6-2 served as a loading control.

\section{miR-20b gene copy number analysis}

Genomic DNAs extracted from IR-exposed HMEC cells using a kit for purification of total DNA from animal blood or cells (QIAGEN) were subjected to real-time PCR using SsoFast EvaGreen Spermix (Bio-Rad) with the following primers; 20bCopyNo-F: 5'-TGC AGG TAG TTT TGG CAT GA-3', 20bCopyNo-R: 5'-TCA ACA AGA GAT TTG TTA TCC AAG AG-3'; RPP38-F: 5'-TGG TTG TGA AGA CGT CGT TGA-3', RPP38-R: 5'-TGC ATA TCC TCG CTC TCC AGA-3'. The copy number level relative to the internal control (RNase P/ RPP38) was calculated by the comparative threshold cycle $(\mathrm{Ct})$ method, and results are shown as fold induction.

\section{Immunofluorescence}

HMEC cells grown on coverslips were exposed to either $30 \mathrm{kVp} / 0.1 \mathrm{~Gy}, 80 \mathrm{kVp} / 2.5 \mathrm{~Gy} \mathrm{X}$-ray or left sham-treatment as a control. 96 hours after irradiation, immunofluorescence staining was performed using rabbit monoclonal antibody against EGR1 (Cell Signaling Technology) as described previously. ${ }^{55}$ Fluorescence was observed under 400x on an inverted microscope (ZEISS).

\section{EGR1 real-time RT-PCR}

Total RNA isolated from HCC1806 transiently transfected with $10 \mathrm{nM}$ or $50 \mathrm{nM}$ of siEGR1 (QIAGEN) or $50 \mathrm{nM}$ of AllStar negative control (QIAGEN) for 96 hours was subjected to real-time RT-PCR using EGR1 primers (QuantiTect Primer Assay, QIAGEN) and SsoFast EvaGreen Supermix (BIO-RAD) according to manufacturer's instruction.

\section{Generation of plasmid constructs}

Wild-type and mutant fragments of the hsa-miR-20b promoter amplified by PCR using genomic DNA were cloned into pGEM-T easy vector (Promega), released by digestion with Kpn I and Hind III, and subcloned into pGL3-Basic vector (Promega); sequence identity was confirmed by automatic sequencing; primers used here 
for amplifying miR-20b promoters are as follows, $20 \mathrm{~b}$ WT-Prom F: 5'-ATT GGT ACC GTT TTC GCT TTG3', 20b mt-Prom F: 5'-TTG GTA CCG AGA CTG CGC T-3', 20b Prom R: 5'-ATA AGC TTG CCC CAA CGA AG-3'. To generate luciferase miR-20b target reporters, oligos corresponding to portions of the 3'UTRs of either PTEN or BRCA1 were synthesized, annealed and cloned into downstream of the luciferase gene in the pGL3-Basic vector between $X b a$ I and EcoR I (a linker introduced by Dr James Meservy); the sequence identity was confirmed by automatic sequencing. Oligo sequences were as follows. PTEN 3'UTR-1: 5'-/5Phos/CTA GAA GAT GGC ACT TTC ACT GCT TGT TGT TTG CGC ATT TTT G-3', PTEN 3'UTR-2: 5'-/5Phos/AAT TCA AAA ATG CGC AAA CAA CAA GCA GTG AAA GTG CCA TCT T-3'; BRCA1 3'UTR-1: 5'-/5Phos/CTA GAT CAC GCC TGT AAT CCC AGC ACT TTG GGA G-3', BRCA1 3'UTR-2: 5'-/5Phos/AAT TCT CCC AAA GTG CTG GGA TTA CAG GCG TGA T-3'.

\section{Bioinformatics}

The transcription start site of hsa-miR-20b was predicted using Promoter 2.0 Prediction Server. Common transcription factor binding sites at hsa-miR-20b promoter were analysed using Genomatix. Potential hsa-miR$20 \mathrm{~b}$ targets were predicted by both MIRANDA and RNAhybrid softwares. A network of predicted hsa-miR20b targets were generated by STRING 9.0.

\section{Cell cycle and apoptosis analyses}

HCC1806 cells grown to $90 \%$ confluency (as determined by microscopy analysis) were transiently transfected with either miRCURY LNA hsa-miR-20b power inhibitor or miRCURY LNA microRNA power inhibitor negative control A (Exiqon). 96 hours after transfection, the cells were harvested for cell cycle and apoptosis analyses that were performed with a BD FACSCanto II Flow Cytometer (BD Biosciences) using propidium iodide staining solution and FITC Annexin V Apoptosis Detection Kit II (BD Biosciences) according to manufacturer's instruction.

\section{Western blot analysis}

HMEC, MCF7, ZR75-1, HCC1419, and HCC 1806 cells grown to $90 \%$ confluency were rinsed twice with ice-cold PBS and scraped off the plate in radioimmunoprecipitation assay buffer (RIPA). 30-100 $\mu \mathrm{g}$ of protein per sample was electrophoresed on $6 \%$ or $10 \%$ SDS-PAGE and electrophoretically transferred to PVDF membrane (Amersham Hybond ${ }^{\mathrm{TM}}-\mathrm{P}, \mathrm{GE}$ Healthcare) at $4^{\circ} \mathrm{C}$ for 1.5 hours. Blots were incubated for 1 hour with
$5 \%$ nonfat dry milk to block nonspecific binding sites and then incubated with polyclonal/monoclonal antibodies against PTEN, BRCA1 (Santa Cruz Biotechnology) or EGR1 (Cell Signaling Technology) at $4^{\circ} \mathrm{C}$ overnight. The immunoreactivity was detected using peroxidaseconjugated antibody and visualized by ECL Plus Western Blotting Detection System (GE Healthcare). The blots were stripped before reprobing with antibodies to GAPDH or actin (Santa Cruz Biotechnology).

\section{MTT assay}

24 hours after transfection with miR-20b inhibitor (Exiqon), $3.0 \times 10^{3} \mathrm{HCC} 1806$ cells were plated in 96-well plates. 3-(4,5-Dimethylthiazol-2-yl)-2,5diphenyltetrazolium bromide assays were carried out using the Cell Proliferation Kit I (Roche Diagnostics GmbH) as described by the manufacturer. The spectrophotometric absorbance of samples was measured at $595 \mathrm{~nm}$ using a microtiter plate reader (FLUOstar Omega, BMG LABTECH).

\section{Wound healing assay}

24 hours after transfection with miR-20b inhibitor (Exiqon), HCC1806 cells were replated in 6-well plates and incubated at $37^{\circ} \mathrm{C}$ in a humidified atmosphere of $5 \%$ $\mathrm{CO}_{2}$ for another 24 hours. The cells were treated with 10 $\mu \mathrm{g} / \mathrm{ml}$ mitomycin $\mathrm{C}$ (Sigma) for 2 hours before injury. The wound healing assay was carried out as described previously[56].

\section{Transient transfection and luciferase assay}

HEK293 cells grown to $90 \%$ confluence in 6-well plates in antibiotic-free DMEM/High Glucose (Thermo Scientific Limited) containing 10\% FBS were transiently cotransfected with either $0.5 \mu \mathrm{g}$ WT-miR20b promoter or MT-miR20b promoter reporter, $0.2 \mu \mathrm{g}$ or $1 \mu \mathrm{g}$ pCB6-Egr1, 5 ng pRL-TK, and left empty vector pCB6 as a control; or contransfected with $0.4 \mu \mathrm{g}$ reporter plasmid (either pGL3-PTEN or pGL3-BRCA1), 5 ng pRL-TK plasmid, $10 \mathrm{nM}$ or $50 \mathrm{nM}$ hsa-miR-20b mimic (5'-CAA AGU GCU CAU AGU GCA GGU AG-3', QIAGEN) and mirVana miRNA mimic negative control \#1 (Ambion) using Lipofectamine 2000 (Invitrogen, Carlsbad, CA, USA) as per manufacturer's instruction. 24 hours after transfection, cells were harvested, the relative luciferase activity was measured by the Dual-Luciferase Reporter Assay System (Promega) using a luminometer (FLUOstar Omega, BMG LABTECH) and with Firefly luciferase data normalized to Renilla luciferase. 


\section{ChIP-PCR}

HMEC and HCC1806 cells grown to $90 \%$ confluence were subjected to quantitative ChIP assays as detailed elsewhere $[57,58]$. Briefly cells were treated with $0.4 \%$ formaldehyde and the cross-linked chromatin retrieved by nuclei isolation and lysis. The chromatin was sonicated to $\sim 300 \mathrm{bp}$, pre-cleared with rabbit serum and immunoprecipitated with ChIP-grade rabbit monoclonal antibody to EGR1 (Cell Signaling Technology). Enrichments were measured by both conventional PCR and real-time PCR using SsoFast EvaGreen Supermix (Bio-Rad) as previously described [58]. The levels of enrichment were normalized to that obtained with total input. The following primer pairs were used; Hu20bEGR1-ChIP-PCR F: 5'-GGA AGA GAG AAG GGC TTT GG-3', HU20B-EGR1-CHIP-PCR R: 5'-TGC CTT TAA TAG CCC AAG GA-3'.

\section{Electrophoretic mobility shift assay (EMSA)}

HCC 1806 cells grown to $90 \%$ confluency, nuclear extracts were prepared using NE-PER Nulcear and Cytoplasmic Extraction Reagents (Thermo Scientific Limited), and EMSA was performed using Lightshift Chemilluminescent EMSA Kit (Thermo Scientific Limited) according to the manufacturer's instruction. $20 \mu 1$ of binding reaction contained $1 \times$ EGR1 binding buffer, $50 \mathrm{ng} / \mu \mathrm{l}$ Poly(dI/dC), 0.05\% NP-40, $800 \mathrm{nM}$ cold probe (20bEGR1-EMSA-Oligo 1: 5'-GGC CGG GTG GGC GGG GGC GGG C-3; 20bEGR1-EMSA-Oligo 2: 5'-GCC CGC CCC CGC CCA CCC GGC C-3'), 2 nM Biotin probe (20bEGR1-EMSA-Biotin 1: 5'-Biotin/GGC CGG GTG GGC GGG GGC GGG C-3'; 20bEGR1EMSA-Biotin 2: 5'-Biotin/ GCC CGC CCC CGC CCA CCC GGC C-3'), $2 \mu 1$ nuclear extract, $1 \mu \mathrm{g} / \mu \mathrm{l} \mathrm{BSA}, 2 \mu \mathrm{l}$ EGR1 antibody or $2 \mu 1$ normal rabbit IgG (Cell Signaling Technology).

\section{Fluorescence in situ hybridization (FISH)}

Hsa-miR-20b expression in breast cancer specimens (BRC961, BRC962 and BRM961 arrays; Pantomics) was determined by FISH as detailed elsewhere[59]. Briefly, after deparafinization, the sections were prehybidized for 20 minutes at $55^{\circ} \mathrm{C}$, followed by 1 hour hybridization at the same temperature with 1:1000 dilution of miRCURY LNA hsa-miR-20b detection probe (Exiqon); after washing, the sections were blocked for 1 hour with blocking solution, and incubated with 1:1000 dilution of anti-Digoxigenin-Fluorescein, Fab fragments (Roche) at $4^{\circ} \mathrm{C}$ overnight.

\section{RNA pulldown and RNA sequencing analysis}

Total RNA isolated from HCC1806 cells using TRIzol Reagent (Invitrogen) and treated RNase-free DNase I (Fermentas) was subjected to RNA pulldown assay using $\mu$ MACS Streptavidin Kit (Miltenyi Biotec Inc.) as described previously [60] and according to the manufacturer's instruction. $15 \mu \mathrm{g}$ of total RNA and 1 $\mu \mathrm{g}$ of biotinylated capture DNA were used in the RNA pulldown, including wild-type miR-20b capture oligo: 5Biosg/CAA AGT GCT CAT AGT GCA GGT AG, and scrambled miR-20b capture oligo: 5Biosg/CCA GTG AAT CAT AGT GCA GGT AG (Exiqon). $300 \mathrm{ng}$ of total pulldown RNA was subjected to high throughput RNA sequencing analysis using our in house sequencing platform (Illumina, Genome Analyser). Sequences with $>2$-fold increase compared to scrambled oligo were pulled out for further analysis. Prediction of miR-20b-targeting mRNAs was performed using MIRANDA and RNAhybrid with default settings $[61,62]$. A network of the predicted tumor suppressors targeted by miR-20b was generated by STRING 9.0.

\section{Immunohistochemical analysis}

The expression of EGR1, PTEN and BRCA1 in breast cancer specimens (BRC961, BRC962 and BRM961 arrays; Pantomics) was determined by immunohistochemical staining using antibodies to EGR1 (Cell Signaling Technology), PTEN and BRCA1 (Biocare Medical, performed by Pantomics) as described by manufacturers. Stained tissue sections were analyzed independently by a pathologist and scientists in blind manner.

\section{Statistical analysis}

The Student's $t$ test was used for statistical significance of differences in miR-20b expression, EGR1 expression, luciferase activity, enrichment of EGR1 at miR-20b promoter, cell growth, and cell migration between groups. Pearson Correlation was used for statistical significance between miR-20b expression and the exression of EGR1 or PTEN or BRCA1 in breast cancer specimens examined. $P<0.05$ was considered significant.

\section{Disclosure of Potential Conflicts of Interest}

No potential conflicts of interest were disclosed.

\section{ACKNOWLEDGEMENTS}

This study was supported by Alberta Cancer 
Foundation/Alberta Innovates-Health Solutions and the Canadian Breast Cancer Foundation grants to Dr. O. Kovalchuk. Dr. B. Wang is a recipient of the Alberta Innovates-Health Solutions Postdoctoral Fellowship. We thank Ms. Lida Luzhna for providing IR-exposed rat mammary gland tissue, and Mr. Julian St. Hilaire for performing the BD FACSCanto II Flow Cytometer.

\section{REFERENCES}

1. Schairer C, Mink PJ, Carroll L, Devesa SS. Probabilities of death from breast cancer and other causes among female breast cancer patients. J Natl Cancer Inst 2004;96:1311-21.

2. Mattsson A, Rudén BI, Hall P, Wilking N, Rutqvist LE. Radiation-induced breast cancer: Long-term follow-up of radiation therapy for benign breast disease. J Natl Cancer Inst 1993;85:1679-85.

3. Doody MM, Lonstein JE, Stovall M, Hacker DG, Luckyanov N, Land CE. Breast cancer mortality after diagnostic radiography: findings from U.S. Scoliosis Cohort Study. Spine (Phila Pa 1976) 2000;25:2052-63.

4. Ronckers CM, Erdmann CA, Land CE. Radiation and breast cancer: a review of current evidence. Breast Cancer Res 2005;7:21-32.

5. Stecklein SR, Jensen RA, Pal A. Genetic and epigenetic signatures of breast cancer subtypes. Front Biosci (Elite Ed) 2012;4:934-49.

6. Bartel DP. MicroRNAs: genomics, biogenesis, mechanism, and function. Cell 2004;116:281-97.

7. Bartel DP. MicroRNAs: target recognition and regulatory functions. Cell 2009;136:215-33.

8. Filipowicz W, Bhattacharyya SN, Sonenberg N. Mechanisms of post-transcriptional regulation by microRNAs: are the answers in sight? Nat Rev Genet 2008;9:102-14.

9. Wang S, Aurora AB, Johnson BA, Qi X, McAnally J, Hill JA, et al. The endothelial-specific microRNA miR-126 governs vascular integrity and angiogenesis. Dev Cell 2008; 15:261-71.

10. Siragam V, Rutnam ZJ, Yang W, Fang L, Luo L, Yang X, Li M, Deng Z, Qian J, Peng C, Yang BB. MicroRNA miR-98 inhibits tumor angiogenesis and invasion by targeting activin receptor-like kinase-4 and matrix metalloproteinase-11. Oncotarget. 2012; 3:1370-85.

11. Zhang B, Pan X, Cobb GP, Anderson TA. microRNAs as oncogenes and tumor suppressors. Dev Biol 2007;302:1-12.

12. Koturbash I, Zemp FJ, Pogribny I, Kovalchuk O. Small molecules with big effects: the role of the microRNAome in cancer and carcinogenesis. Mutat Res 2011;722:94-105.

13. Tanzer A, Stadler PF. Molecular evolution of a microRNA cluster. J Mol Biol 2004;339:327-35.

14. Hayashita Y, Osada H, Tatematsu Y, Yamada H, Yanaqisawa $\mathrm{K}$, Tomida $\mathrm{S}$, et al. A polycistronic microRNA cluster, miR-17-92, is overexpressed in human lung cancers and enhances cell proliferation. Cancer Res 2005;65:962832 .

15. Matsubara $H$, Takeuchi $T$, Nishikawa E, Yanaqisawa K, Hayashita Y, Ebi H, et al. Apoptosis induction by antisense oligonucleotides against miR-17-5p and miR$20 \mathrm{~b}$ in lung cancers overexpressing miR-17-92. Oncogene 2007;26:6099-105.

16. Landais S, Landry S, Legault P, Rassart E. Oncogenic potential of the miR-106-363 cluster and its implication in human T-cell leukemia. Cancer Res 2007;67:5699-707.

17. Inomata M, Tagawa H, Guo YM, Kameoka Y, Takahashi N, Sawada K. MicroRNA-17-92 down-regulates expression of distinct targets in defferent B-cell lymphoma subtypes. Blood 2009; 113:396-402.

18. Li H, Yang BB. Stress response of glioblastoma cells mediated by miR-17-5p targeting PTEN and the passenger strand miR-17-3p targeting MDM2. Oncotarget 2012;3:1653-1668.

19. Katada T, Ishiguro H, Kuwabara Y, Kimura M, Mitui A, Mori Y, et al. microRNA expression profile in undifferentiated gastric cancer. Int J Oncol 2009;34:537-42.

20. Sun Y, et al. Expression profile of microRNAs in c-Myc induced mouse mammary tumors. Breast Cancer Res Treat 2009;118:185-96.

21. Castellano L, Giamas G, Jacob J, Coombes RC, Lucchesi $\mathrm{W}$, Thiruchelvam $\mathrm{P}$, et al. The estrogen receptor- $\alpha$-induced microRNA signature regulates itself and its transcriptional response. PNAS 2009;106:15732-7.

22. Cascio S, D'Andrea A, Ferla R, Surmacz E, Gulotta E, Amodeo V, et al. miR-20b modulates VEGF expression by targeting HIF-1 alpha and STAT3 in MCF-7 breast cancer cells. J Cell Physiol 2010;224:242-9.

23. Koturbash I, Zemp FJ, Kutanzi K, Luzhna L, Loree J, Kolb $\mathrm{B}$, et al. Sex-specific microRNAome deregulation in the shielded bystander spleen of cranially exposed mice. Cell Cycle 2008;7:1658-67.

24. Morgan WF, Day JP, Kaplan MI, McGhee EM, Limoli CL. Genomic instability induced by ionizing radiation. Radiat Res 1996;146:247-58.

25. Muthukkumar S, Nair P, Sells SF, Maddiwar NG, Jacob RJ, Rangnekar VM. Role of EGR-1 in thapsigargin-inducible apoptosis in the melanoma cell line A375-C6. Mol Cell Biol 1995;15:6262-72.

26. Nguyen HQ, Hoffman-Liebermann B, Liebermann DA. The zinc finger transcription factor Egr-1 is essential for and restricts differentiation along the macrophage lineage. Cell 1993;72:197-209.

27. Santiago FS, Atkins DG, Khachigian LM. Vascular smooth muscle cell proliferation and regrowth after mechanical injury in vitro are Egr-1/NGFI-A-dependent. Am J Pathol 1999;155:897-905.

28. Sukhatme VP, Cao XM, Chang LC, Tsai-Morris $\mathrm{CH}$, Stamenkovich D, Ferreira PC, et al. A zinc fingerencoding gene coregulated with c-Fos during growth 
and differentiation, and after cellular depolarization. Cell 1988;53:37-43.

29. Khachigian LM, Lindner V, Williams AJ, Collins T. Egr1-induced endothelial gene expression: a common theme in vascular injury. Science 1996;271:1427-31.

30. Khachigian LM, Collins T. Early growth response factor 1 : a pleiotropic mediator of inducible gene expression. J Mol Med (Berl) 1998;76:613-6.

31. Khachigian LM. Early growth response-1 in cardiovascular pathobiology. Circ Res 2006;98:186-191.

32. Santiago FS, Lowe HC, Day FL, Chesterman CN, Khachigian LM. Early growth response factor-1 induction by injury is triggered by release and paracrine activation by fibroblast growth factor-2. Am J Pathol 1999;154:937-44.

33. Delbridge GL, Khachigian LM. FGF-1-induced plateletderived growth factor-A chain gene expression in endothelial cells involves transcriptional activation by early growth response factor-1. Circ Res 1997;81:282-8.

34. Wang B, Khachigian LM, Esau L, Birrer MJ, Zhao X, Parker MI, et al. A key role for Early growth response-1 and nuclear factor- $\kappa \mathrm{B}$ in mediating and maintaining $\mathrm{GRO} /$ CXCR2 proliferative signaling in esophageal cancer. Mol Cancer Res 2009;7:755-64.

35. Chen A, Xu J, Johnson AC. Curcumin inhibits human colon cancer cell growth by suppressing gene expression of epidermal growth factor receptor through reducing the activity of the transcription factor Egr-1. Oncogene 2006;25:278-87.

36. Eid MA, Kumar MV, Iczkowski KA, Bostwick DG, Thindall DJ. Expression of early growth response genes in human prostate cancer. Cancer Res 1998;58:2461-8.

37. Svaren J, Ehrig T, Abdulkadir SA, Ehrengruber MU, Watson MA, Milbrandt J. EGR1 target genes in prostate carcinoma cells identified by microarray analysis. J Biol Chem 2000;275:38524-31.

38. Mitchell A, Dass CR, Sun LQ, Khachigian LM. Inhibition of human breast carcinoma proliferation, migration, chemoinvasion and solid tumor growth by DNAzymes targeting the zinc finger transcription factor EGR-1. Nucleic Acids Res 2004;32:3065-9.

39. Baron V, Duss S, Rhim J, Mercola D. Antisense to the early growth response-1 gene (Egr-1) inhibits prostate tumor development in TRAMP mice. Ann N Y Acad Sci 2003;1002:197-216.

40. Azmi AS, Banerjee S, Ali S, Wang Z, Bao B, Beck FW $\mathrm{J}$, et al. Network modeling of MDM2 inhibitor-Oxaliplatin combination reveals biological synergy in wt-p53 solid tumors. Oncotarget 2011;2:378-392.

41. Boone DN, Hann SR. The Myc-ARF-Egr1 pathway: unleashing the apoptotic power of c-Myc. Cell Cycle 2011;10:2043-2044.

42. Sharma A, Kumar M, Aich J, Hariharan M, Brahmachari SK, Agrawal A, et al. Posttranscriptional regulation of interleukin-10 expression by hsa-miR-106a. PNAS
2009;106:5761-6.

43. Davies MA, Kim SJ, Parikh NU, Dong Z, Bucana CD, Gallick GE. Adenoviral-mediated expression of MMAC/ PTEN inhibits proliferation and metastasis of human prostate cancer cells. Clin Cancer Res 2002;8:1904-14.

44. Chen WJ, Lin KH, Lai YJ, Yang SH, Pang JH. Protective effect of propylthiouracil independent of its hypothyroid effect on atherogenesis in cholesterol-fed rabbits: PTEN induction and inhibition of vascular smooth muscle cell proliferation and migration. Circulation 2004;110:1313-9.

45. Zhang LY, Ho-Fun Lee V, Wong AM, Kwong DL, Zhu YH, Dong SS, et al. MicroRNA-144 promote cell proliferation, migration and invasion in nasopharyngeal carcinoma through repression of PTEN. Carcinogenesis 2013;34:454-63.

46. Sobol H, Stoppa-Lyonnet D, Bressac-de-Paillerets B, Peyrat JP, Kerangueven F, Janin N, et al. Truncation at conserved terminal regions of BRCA1 protein is associated with highly proliferating hereditary breast cancers. Cancer Res 1996;56:3216-9.

47. Wang H, Shao N, Ding QM, Cui J, Reddy ES, Rao VN. BRCA1 proteins are transported to the nucleus in the absence of serum and splice variants BRCA1a, BRCA1b are tyrosine phosphoproteins that associate with E2F, cyclins and cyclin dependent kinases. Oncogene 1997;15:143-57.

48. Petrocelli T, Slingerland JM. PTEN deficiency: a role in mammary carcinogenesis. Breast Cancer Res 2001;3:35660.

49. Roy R, Chun J and Powell SN. BRCA1 and BRCA2: different roles in a common pathway of genome protection. Nat Rev Cancer 2011;12:68-78.

50. Ory B and Ellisen LW. A microRNA-dependent circuit controlling p63/p73 homeostasis: p53 family cross-talk meets therapeutic opportunity. Oncotarget 2011;2:259-264.

51. Virolle T, Adamson ED, Baron V, Birle D, Mercola D, Mustelin T, et al. The Egr-1 transcription factor directly activates PTEN during irradiation-induced signaling. Nat Cell Biol 2001;3:1124-1128.

52. Chang $\mathrm{S}$ and Sharan SK. Epigenetic control of an oncogenic microRNA, miR-155, by BRCA1. Oncotarget 2012;3:5-6.

53. Gadaleta E, Cutts RJ, Kelly GP, Crnogorac-Jurcevic T, Kocher HM, Lemoine NR, et al. A global insight into a cancer transcriptional space using pancreatic data: importance, findings and flaws. Nucleic Acids Res 2011;39:7900-7.

54. Radojicic J, Zaravinos A, Vrekoussis T, Kafousi M, Spandidos DA, Stathopoulos EN. MicroRNA expression analysis in triple-negative (ER, PR and Her2/neu) breast cancer. Cell Cycle 2011;10:507-517.

55. Wang B, Chen J, Santiago FS, Janes M, Kavurma MM, Chong $\mathrm{BH}$, et al. Phosphorylation and acetylation of histone $\mathrm{H} 3$ and autoregulation by early growth response 1 mediate interleukin $1 \beta$ induction of early growth response 1 transcription. Arterioscler Thromb Vasc Biol 2010;30:536- 
45.

56. Yi T, Cho SG, Yi Z, Pang X, Rodriguez M, Wang Y, et al. Thymoquinone inhibits tumor angiogenesis and tumor growth through suppressing AKT and extracellular signalregulated kinase signaling pathways. Mol Cancer Ther 2008;7:1789-96.

57. Nelson JD, Denisenko O and Bomsztyk K. Protocol for the fast chromatin immunoprecipitation (ChIP) method. Nat Protoc 2006;1:179-85.

58. Pimanda JE, Chan WY, Donaldson IJ, Bowen M, Green AR, Göttgens B. Endoglin expression in the endothelium is regulated by Fli-1, Erg, and Elf-1 acting on the promoter and a -8-kb enhancer. Blood 2006;107:4737-45.

59. de Planell-Saguer M, Rodicio MC, Mourelatos Z. Rapid in situ codetection of noncoding RNAs and proteins in cells and formalin-fixed paraffin-embedded tissue sections without protease treatment. Nat Protoc 2010;5:1061-73.

60. Hsu RJ, Yang HJ, Tsai HJ. Labeled microRNA pull-down assay system: an experimental approach for high-throughput identification of microRNA-target mRNAs. Nucleic Acids Res 2009;37:e77.

61. Enright AJ, John B, Gaul U, Tuschl T, Sander C and Marks DS. MicroRNA targets in Drosophila. Genome Biol 2003;5(1):R1.

62. Rehmsmeier M, Steffen P, Höchsmann M, Giegerich R. Fast and effective prediction of microRNA/target duplexes. RNA 2004;10:1507-17. 